7-31-2018

\title{
Promoting Internationalization at home in ASEAN Higher Education Institutions: A proposed project
}

Jamshed Khalid

Universiti Sains Malaysia, jamshed.jt@gmail.com

Anees Janee Ali

School of Management, Universiti Sains Malaysia

Follow this and additional works at: https://scholarhub.ui.ac.id/ajce

Part of the Social and Behavioral Sciences Commons

\section{Recommended Citation}

Khalid, Jamshed and Ali, Anees Janee (2018). Promoting Internationalization at home in ASEAN Higher Education Institutions: A proposed project. ASEAN Journal of Community Engagement, 2(1).

Available at: https://doi.org/10.7454/ajce.v2i1.106

Creative Commons License

(c) (i) ()

This work is licensed under a Creative Commons Attribution-Share Alike 4.0 License.

This Research Article is brought to you for free and open access by the Universitas Indonesia at ASEAN Journal of Community Engagement. It has been accepted for inclusion in ASEAN Journal of Community Engagement. 


\title{
Promoting internationalization at Home in ASEAN Higher Education Institutions: A Proposed Project Jamshed Khalida ${ }^{*}$, Anees Janee Ali ${ }^{b}$ \\ aUniversiti Sains Malaysia, Malaysia \\ bSchool of Management, Universiti Sains Malaysia, Malaysia
}

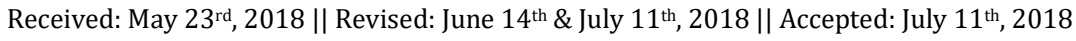

\begin{abstract}
Globalization has a profound impact on the higher education institutions to build graduates capable to work and compete in the fourth industrial revolution. The Association of Southeast Asian Nations (ASEAN) region is no exception to this movement. Students graduated from overseas gain a global exposure through intercultural competencies in the diverse and multicultural environment. However, there is a high ratio of immobile students who need to be skilled with global competencies such as intercultural communication, knowledge and awareness about diverse cultures, and understanding of international and global challenges. Internationalization at home is considering an apt solution for such challenges but, unfortunately, neglected by higher education institutions (HEIs) administration and policymakers in ASEAN due to the incomprehension regarding potential benefits linked with this change. The aim of this proposed project is to identify and operationalize the solutions for the deficiency of global and international competencies among the immobile students in ASEAN countries. Through involving professionals from diverse culture and backgrounds, and by conducting information sharing activities on internationalization at home (IaH) i.e. workshops, symposiums, and training, it is expected that this project will bring a societal change through signifying the need of internationalization at home. The findings of the project would be highly significant for HEIs administration, education ministries, and corporate professionals to achieve the workforce demands such as global graduates capable to move efficiently in the rapidly changing global markets.
\end{abstract}

Keywords: internationalization at home, ASEAN higher education, global graduates, intercultural competence

\section{Introduction}

Increasing students' exposure to global and international contexts and enlightening their intercultural competencies remain challenging educational objectives, particularly in the developing regions (Jon, 2013; Deardorff, 2011). Fortunately, the recent shift in academics from study abroad opportunities toward 'internationalization at home' initiatives, where domestic students learn through interaction with people from diverse cultures while staying at their home campuses, offering new openings and opportunities. Scholars seem to create a consensus that contact with distinct cultures is indispensable for encouraging international learning and enhancing intercultural competencies among groups (Beelen \& Jones, 2015). Allport's (1954) contact hypothesis recommends that interaction between groups is an especially appropriate way to reduce prejudice, stereotyping, and discrimination and to attain intercultural competency objectives.

The demands of campus-based internationalization are growing worldwide, and ASEAN is no exception to this. ASEAN is putting greater efforts in refining its policies to meet the challenges of global higher education (McBurnie \& Ziguras, 2001; Nguyen, 2009). On a regional level, the notable initiatives of ASEAN include EU-SHARE Program which is based on ASEAN and Europe collaboration to promote policy dialogues, Quality Assurance and 
ASEAN Qualifications Reference Frameworks, Credit Transfer System, and Student Mobility by offering different Scholarships (Yang, 2012; Rumbley, Altbach, \& Reisberg, 2012). SEAMEO-RIHED, on the other hand, facilitating university networks development such as the ASEAN International Mobility for Students Programme (AIMS), Greater Mekong Sub-region University Consortium (GMS-UC), and ASEAN-China Network for Cooperation and Exchanges (ACNET-EngTech) (Bhandari \& Lefébure, 2015).

Though the mobility is growing rapidly and has resulted in numerous benefits, disparities in study abroad participation is still a concern for higher education institutions (HEIs). According to Dessoff (2006), students of colors are less likely to go abroad for educational purpose compared to white students. Research has emphasized that several factors stimulus underrepresented students' decisions to stay at home, including fears of different encountering racism and familial obligations/ concerns (Carter, 2006; Dessoff, 2006). Salisbury, Paulsen, and Pascarella (2011) also suggest that study abroad participation may appear as a potential exposure to stereotype threat to African American students. Some other barriers explored by previous researchers are the excessive cost of study abroad, fear of going to unfamiliar places, and minority group marginalization (Poyrazli \& Grahame, 2007; Yeh \& Inose, 2003; Smith \& Khawaja, 2011).

These arguments show that mobility is largely restricted which in turn limits the students' ability to acquire international, intercultural and global competences. What other steps can be initiate to substitute mobility in order to produce global graduates? This question brings the idea of Internationalization at Home ( $\mathrm{IaH})$ that includes all students for global and international education, regardless whether they are "internationally mobile or not" (Teekens, 2007; Mestenhauser, 2011). As Ackers (2008) states; "internationalization is not the same thing as mobility" (p.424). Researchers have recommended that diversity between local and international students can facilitate the recognition of IaH (Paige, 2004; Leask, 2009). Engaging both domestic and international students by involving in curricular, cocurricular, and extracurricular activities can enhance their mutually beneficial experiences.

Amid these challenges, various concerns are growing regarding domestic students who are unable to participate in study abroad resulting in lack of global and international competencies as their peers (Bentao, 2011; Brandenburg \& De Wit, 2015). Therefore, there is a need to institutionalize internationalization at home ( $\mathrm{IaH}$ ) to develop an environment fit to produce global graduates without leaving home. This project, thus, aims to highlight the need and enlighten the linked benefits of IaH in ASEAN higher education institutions.

\subsection{Conceptualization of Internationalization at Home (IaH)}

Internationalization at Home ( $\mathrm{IaH})$ is a new concept in the internationalization of higher education field. The term was coined around 2001 by Hanneke Teekenns and her team at Nuffic, The Netherlands, and since then has received active reviews and actions from the higher education institutions (HEIs) across Europe and northern America. While IaH has received active debates, discussions, and implications in the developed parts of the world, unfortunately, this topic has not been taken seriously among the HEIs in the ASEAN region (Horn, Hendel \& Fry, 2012; Hong \& Songan; 2011). Therefore, this project is mainly about introducing IaH in an appropriate way, creating high interest and bringing the HEIs in the ASEAN to understand and take certain steps since the linked benefits to this change are plentiful for students, HEIs as well as societal development. 
Jamshed Khalid, Anees Janee Ali | ASEAN Journal of Community Engagement | Volume 2, Number 1, 2018

The latest definition of IaH is given by Beelen and Jones (2015): "the purposeful integration of international and intercultural dimensions into the formal and informal curriculum for all students within domestic learning environment". Knight (2006) differentiates internationalization into two streams, namely internationalization abroad and internationalization at home ( $\mathrm{IaH})$ which are interdependent. She emphasizes that internationalization abroad involves all forms of cross borders education, the mobility of academicians, students, scholars, curriculum and research projects. Internationalization at Home (IaH), on the other hand, contains activities that encourage students to develop global mindedness, intercultural skills, and international understanding. An internationalized curriculum and domestic and international students' interaction through co-curricular and extra-curricular activities are at the heart of this concept.

\section{Methods}

\subsection{Pilot-interviews}

The pilot interviews have been conducted through telephone conversations. Both public and private universities have been targeted from selected five countries such as Malaysia, Indonesia, Thailand, The Philippines and Myanmar. Most of the respondents were lecturers and staff members of international offices of universities. To get an appointment, the respondents have been contacted by email with an explanation of the objective and importance of this research. The interviews were comparatively short with an average time period of 15 - 20 minutes. The basic four questions asked from the respondents are given below.

(1) What is Internationalization at Home to you?

(2) Do you think your institution is practicing Internationalization at Home?

(3) What are your views about immobile students who are not able to travel abroad for higher education and lack of international and global competences?

(4) Do you think that Internationalization at Home can play a role in overcome challenges of rapidly changing world and help out graduates to meet the demands of local and international employers?

\subsection{Findings from the secondary data investigation and pilot-interviews}

The findings from the available literature and through telephonic pilot-interviews from the university administrators from five ASEAN countries (Malaysia, Indonesia, Thailand, The Philippines and Myanmar) certainly indicate that internationalization at home (IaH) concept is highly demanding in the higher education institutions (HEIs) across ASEAN region. We found lack of institutional policies, low awareness, and inappropriate training that hinder these HEIs to move forward in internationalizing their institutions. Thus, this proposed project is established at the right time and at the right place to share knowledge, guidance, and training of IaH to the HEIs across ASEAN region, which not only benefits the students to become global citizens but also the HEIs and their stakeholders.

Here are some findings of the interviews that have been conducted on the IaH issue among the five targeted countries of this project. In Malaysia, generally, the five top-ranking universities are aware of $\mathrm{IaH}$ and have been practicing this concept by improving the curriculum with international flavors and lately with outside-of-the-classroom activities. However, lecturers and staff of international offices are not fully aware of this concept. 
Majority of the interviewees appreciated the concept of IaH and supported the idea of promoting global competences of students without leaving home.

In Indonesia, with over 4000 HEIs across the nation, only about 200 HEIs are with the International Office, an office that is responsible for the internationalization process and activities at the HEIs. This clearly shows how important to have IaH activities at Indonesian HEIs so as the vast majority of immobile students have the opportunity to be internationalized at their home campuses.

Thailand, a country that practices an open-door policy to foreigners since hundreds of years ago, is also facing inadequacy when dealing with IaH. Many HEIs are not fully utilizing and practicing the IaH resulting in low global competencies among graduates.

In the Philippines, the Ministry of Higher Education encourages HEIs to be active in implying internationalization but only a few top universities are taking up this movement. With many students eager to travel overseas but facing a lack of resources, IaH is an opportunity to carry out an international way of teaching and learning in HEIs in The Philippines.

Myanmar, being a young country, is full of young people at HEIs who are eager to have prominence globally. However, the opportunities are quite limited due to financial issues. Nonetheless, there are some HEIs that are striving for internationalization. Yet, they still need guidance and training on this matter.

Based on the interviews, the first conclusion that we derived is that many HEIs in the ASEAN countries do not put considerable efforts in implementing IaH at their institutions. Unfortunately, there were some universities which are not aware of this concept and need guidance on how to implement IaH at their institutions. Secondly, the majority of the universities put so much emphasis on student exchange program, which is one of the elements of internationalization of HEIs. However, universities need to think that this international exchange program will reach its saturation level which may result in high competition for students to be accepted to follow the program at other overseas universities due to the unbalanced number of the incoming and outgoing students. This future predicted scenario, thus, put more emphasis for HEIs in the ASEAN region to consider and implemented internationalization at home to give opportunities to all students to be exposed and experience internationalization and learn from cultural differences without traveling to other countries.

\section{Results and Discussions}

\subsection{The content of proposed project and methods in selected five ASEAN countries}

\subsubsection{Internal meetings and in-country review}

Physical and skype meetings will be conducted among the three principal project members. These meetings are to discuss our plan of how to conduct the project in the proper way and to meet milestones and target of the project in the specific time period. In addition, this meeting will discuss how to handle the budget and to do the necessary bookings and reservations to conduct workshops in the five selected countries

\subsubsection{Site visits to selected universities in the five countries}

In a span of two days, four universities will be visited to know the current situations of IaH practiced at the institutions. Interviews with the key players of Internationalization process in the universities will be carried out. In addition, a meeting with about 20 students 
from each university will be conducted to find out their views about IaH and what are they looking for in the IaH program.

\subsubsection{First series workshops}

During the first year, a two-day workshop will be conducted in each country for the practitioners of IaH at HEIs. The first workshop is meant for practitioners, especially the Directors of International Offices in universities to come together and discuss the need or implementation process of the internationalization at their institutions. A group of 20 International Office Directors from 20 higher education institutes will be invited to participate in the workshop.

An expert of internationalization from each country will be invited to deliver a talk to the participants. In addition, a survey will be conducted among the participants to see the current trends of IaH practice at each of the HEIs. This gathered data will be analyzed and later discussed in the workshop and will be used again during the second workshop in the following year. On top of that, the participants are asked to plan activities related to IaH for the following one year because there will be a second workshop conducted for them in the following year. 


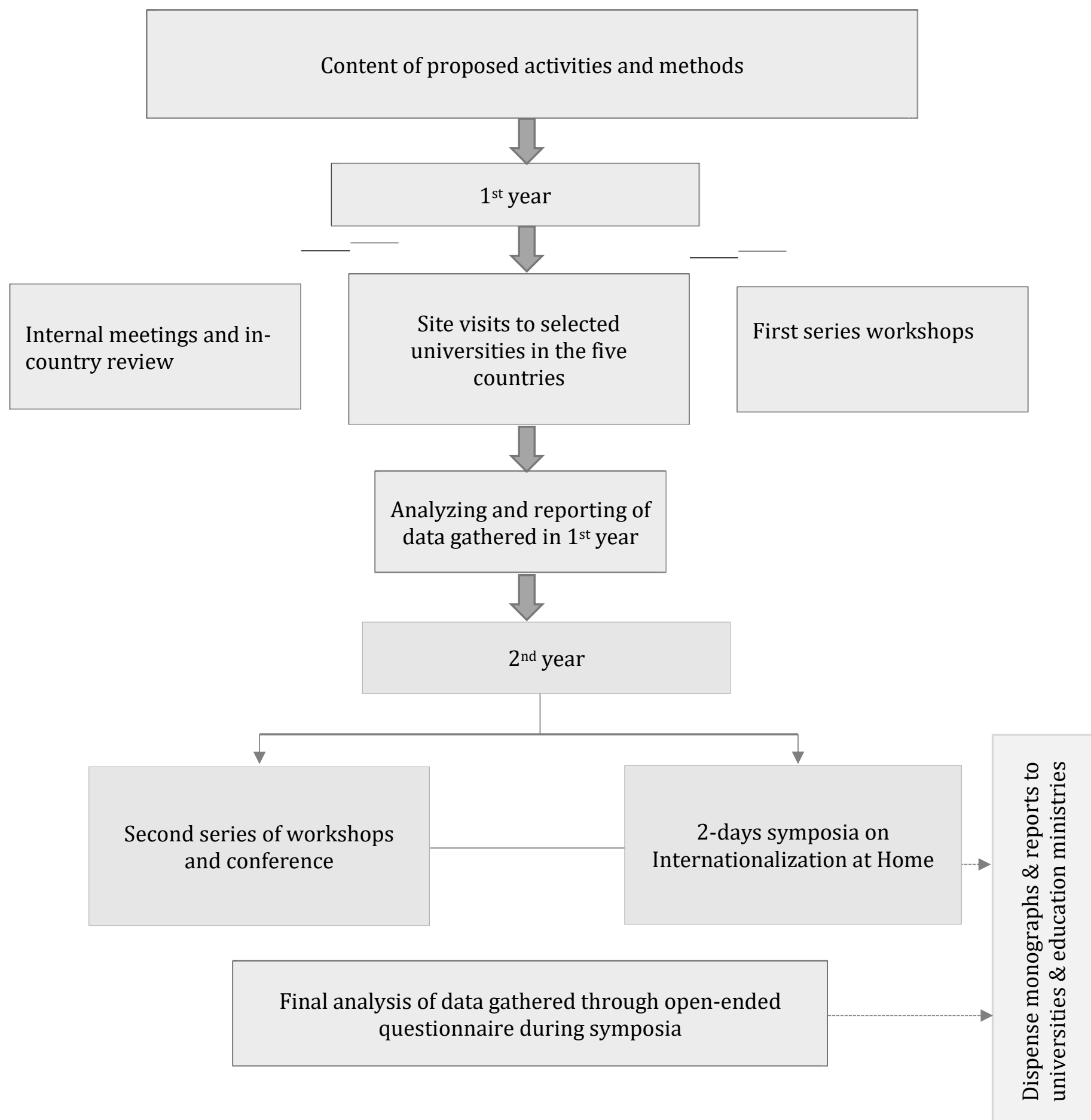

Fig. 1 Contents of activities for two years

In the first workshop, participants will be exposed to the knowledge and information of IaH since it is a new concept in the HEIs. Many key players of Internationalization of HEIs are not fully aware of the know-how to conduct IaH. Thus, this workshop will introduce the concept of IaH and what activities required at the institutional level to promote this concept. 
Jamshed Khalid, Anees Janee Ali | ASEAN Journal of Community Engagement | Volume 2, Number 1, 2018

In addition, participants will be asked to share with their colleagues as this session has a two-pronged strategy: to get to know what is going on and for others to learn from each other. The data will be collected from the participants in the form of questionnaire and group discussion which will be analyzed later to evaluate the key trends of IaH in ASEAN region.

\subsubsection{Review on each country}

From the site visits to four universities and by conducting workshops (as shown in figure 1), a review will be made to see the trend and situation of IaH. Summaries and conclusions from the visits and workshops will be written and will serve as guidelines for the principal project members to prepare them for the second workshop in the following year.

\subsection{Activities Planned for the Second Year}

\subsubsection{Second series of workshops and conference}

This special conference is meant for the benefactors of IaH which include students and HEIs officers that are directly involved in IaH such as lecturers, International Office officers and also the top management of the HEIs. 200 participants are expected, in which 10 persons from each of the 20 participating institutions are invited. In addition, officers from the Ministry of Higher Education of each country will also be invited to attend the conference. Among others, the conference will be filled with talks about IaH to give a clearer picture of what IaH is about and the importance of IaH for the students' future in becoming a global citizen.

\subsubsection{A 2-day symposium on Internationalization at Home (IaH)}

A special symposium on internationalization at home (IaH) will be conducted in one of the capital cities of the targeted countries for about 250 participants. Participants are invited from the ASEAN and the Asia Pacific region, mainly for the IaH practitioners, students, officers from the education ministries and industrial representatives. Registration will be free, and food and beverages will be provided. In this symposium, an expert in IaH, we propose Professor Jos Beeleen from The Netherlands, will be invited. She will deliver a talk on IaH and conduct a forum in which participants are free to interact with her. In addition, she will also discuss her research on IaH and the way to move forward in the practicing IaH. At the same time, an expert on Internationalization from the ASEAN region will also be invited.

Among the planned activities for the symposium are talks, discussions, forum and a special session for students. Among the topics of to be discussed may be: "Introduction of IaH and who will benefit from it" "The way to move forward with IaH", "Activities leading to effective IaH".

\subsection{Project aims and objectives}

The aim of this project is to identify and operationalize the solutions for the deficiency of global and international competencies among the immobile students from selected ASEAN countries. This project will promote awareness regarding the importance of IaH to the HEIs, academic practitioners, and students across ASEAN region. Besides, knowledge sharing is another objective of this proposed project in order to increase the know-how of IaH with HEIs across ASEAN region through workshops organized for practitioners, conferences for 
students (both local and international, undergraduates and also postgraduates will be involved), and symposium, in which experts from Europe will be invited to share their knowledge and expertise, while participation will be open to practitioners and students across ASEAN. The recent internationalization trends in Southeast Asia can be observed by implementation of this project in ASEAN. This trend and information will be shared with other countries and the best practices and the most suitable ones are to be proposed as the IaH concept to be useful for the ASEAN. This is because ASEAN needs an IaH concept that is tailored and suitable for its region compared to the ones proposed by experts from European and North American countries. Through the planned activities, the usefulness of Internationalization at the Home concept and activities to the HEIs in the ASEAN will be encouraged in order to enhance global citizenship among HEIs students. Lastly, this project has an aim to raise awareness and urge to practice IaH at HEIs across ASEAN region by conducting workshops and training for the practitioners, conferences for students and a symposium for a larger audience of practitioners and students of ASEAN HEIs.

\subsubsection{Reasons for having mutual learning and interactions}

Mutual learning is an effective way to learn and share knowledge with each other in order to promote and enhance the know-how of conducting Internationalization at Home (IaH). It would be helpful in gathering information on the current stage/trends of IaH practice among the HEIs in the ASEAN region. To examine and propose the best practice of IaH programmes that best suits the HEIs in the ASEAN region, mutual learning activities will be helpful. When the best practiced of IaH programmes is proposed and documented, then recommendations can be forwarded to the International Office and top management of HEIs. These recommendations also will be sent to the policymakers in HEIs and education ministries in the form of monographs.

\subsubsection{Goals for mutual learning and project members/practitioners' exchange}

From the gathering of the project members and through workshops conducted for the practitioners of Internationalization at Home (IaH) at higher education institutions (HEIs), conferences for students and a symposium that will have a bigger audience with invited experts in the IaH, it is hoped that better understanding and knowledge of IaH is sought among the practitioners to improve and implement IaH policy at their own institutions. IaH is a new concept introduced and highly practiced by HEIs in the European and North American nations. The policy that they recommend suit best in their regional scenario. Since there is no initiative taken in the ASEAN region to come together on IaH, this project is seen to be the stepping stone in promoting and enhancing IaH at HEIs through the mutual learning and discussions of the project members and practitioners. The mutual learning of the project members and practitioners through workshops, conference and symposium and continuous communication is expected to prepare a sound policy on IaH that can be applied to HEIs across the ASEAN region.

\subsubsection{Tangible outputs expected impacts and mid-long-term vision after completion of the} project

a) Tangible outputs \& expected impacts

i. Documents: Monograph, articles, reports 
Jamshed Khalid, Anees Janee Ali | ASEAN Journal of Community Engagement | Volume 2, Number 1, 2018

ii. Workshops for practitioners

iii. Conference for students, practitioners, and officers from Ministry of Higher Education

iv. Symposium: practitioners at HEIs, Ministry of Higher Education, IO staff and top management and international companies

b) Mid-long-term vision after completion of the project

i. Universities to practice IaH progressively to benefit students

ii. HEIs are aware of the importance of IaH

iii. HEIs to make changes/improvements in the curriculum, activities at the institution,

iv. extra-curricular activities, international activities

v. Introduce courses having an international flavor

\section{Conclusion}

ASEAN countries have a desire for academic excellence, accessibility, quality and international cooperation to compete and participate in the global higher education market. Notwithstanding that there are myriad efforts made by the ASEAN countries to promote internationalization, the efforts to develop a culture of global citizenship at HEIs is still challenging and demanding contemplation. Thus, this proposed project will be helpful in exploring the trends and opportunities of Internationalization at Home and practiced a way for the implementation in the HEIs in ASEAN to produce holistic global graduates for the $21^{\text {st }}$ century.

\section{References}

Ackers, L. (2008). Internationalisation, mobility and metrics: A new form of indirect discrimination? Minerva, 46, 411-435.

Beelen, J., \& Jones, E. (2015). Redefining internationalization at home. In the European Higher Education Area (pp. 59-72). Springer, Cham.

Bentao, Y. (2011). Internationalization at home: the path to internationalization in Chinese research universities. Chinese Education \& Society, 44(5), 84-96.

Bhandari, R., \& Lefébure, A. (Eds.). (2015). Asia: The Next Higher Education Superpower? New York: Institute of International Education.

Brandenburg, U., \& De Wit, H. (2015). The end of internationalization. International higher education, (62).

Carter, D. F. (2006). Key issues in the persistence of underrepresented minority students. New directions for institutional research, 2006(130), 33-46.

Deardorff, D. K. (2011). Assessing intercultural competence. New directions for institutional research, 2011(149), 65-79.

Dessoff, A. (2006). Who's not going abroad? International Educator, 15(2), 20.

Hong, K. S., \& Songan, P. (2011). ICT in the changing landscape of higher education in Southeast Asia. Australasian Journal of Educational Technology, 27(8).

Horn, A. S., Hendel, D. D., \& Fry, G. W. (2012). The empirical basis for adopting a civic rationale for internationalization. Higher Education, 64(2), 161-175. 
Jon, J. E. (2013). Realizing internationalization at home in Korean higher education: Promoting domestic students' interaction with international students and intercultural competence. Journal of Studies in International Education, 17(4), 455-470.

Leask, B. (2009). Using formal and informal curricula to improve interactions between home and international students. Journal of studies in international education, 13(2), 205-221.

McBurnie, G., \& Ziguras, C. (2001). The regulation of transnational higher education in Southeast Asia: Case studies of Hong Kong, Malaysia and Australia. Higher Education, 42(1), 85-105.

Mestenhauser, J. A. (2011). Reflections on the past, present, and future of internationalizing higher education: Discovering opportunities to meet the challenges. Global Programs and Strategy Alliance at the University of Minnesota.

Nguyen, A. (2009). The role of regional organizations in East Asian regional cooperation and integration in the field of higher education. Available at: http://www.wasedagiari.jp/sysimg/imgs/20090410 arir report.pdf. Accessed 12 Mar 2012.

Paige, R. M. (2004). Instrumentation in intercultural training. Handbook of intercultural training, 3, 85-128.

Poyrazli, S., \& Grahame, K. M. (2007). Barriers to adjustment: Needs of international students within a semi-urban campus community. Journal of instructional Psychology, 34(1), 28.

Rumbley, L. E., Altbach, P. G., \& Reisberg, L. (2012). Internationalization within the higher education context. The SAGE handbook of international higher education, 3-27.

Salisbury, M. H., Paulsen, M. B., \& Pascarella, E. T. (2011). Why do all the study abroad students look alike? Applying an integrated student choice model to explore differences in the factors that influence white and minority students' intent to study abroad. Research in Higher Education, 52(2), 123-150.

Smith, R. A., \& Khawaja, N. G. (2011). A review of the acculturation experiences of international students. International Journal of Intercultural Relations, 35(6), 699-713.

Teekens, H. (2007). Internationalisation at home: An introduction. In H. Teekens (Ed.), Internationalisation at home: Ideas and ideals (Vol. 20, pp. 3-11). Amsterdam: EAIE.

Yang, R. (2012). Internationalization, regionalization, and soft power: China's relations with ASEAN member countries in higher education. Frontiers of Education in China, 7(4), 486-507.

Yeh, C. J., \& Inose, M. (2003). International students reported English fluency, social support satisfaction, and social connectedness as predictors of acculturative stress. Counselling Psychology Quarterly, 16(1), 15-28. 